\title{
$\mathbb{C} O \mathbb{G} \mathbb{N} \mathbb{C} \widetilde{\mathbb{A}} O \quad \mathbb{E} O \mathbb{R} G \mathbb{A} \mathbb{N} \mathbb{A} \mathscr{C} \widetilde{\mathbb{A}} O:$

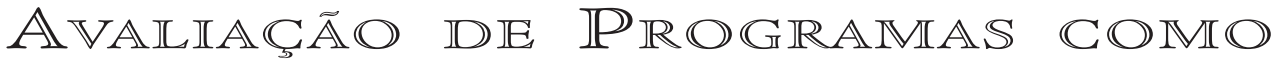 $\mathbb{I} \mathbb{S} \mathbb{T} \hat{A} \mathbb{N} \mathbb{A} \quad \mathbb{P} O \mathbb{R} U \mathbb{T} O \mathbb{R} \mathbb{A} \mathbb{E}$ $\mathbb{S} \mathbb{E} \mathbb{N} \mathbb{I} \mathbb{O S}$ \\ Anderson Veloso Vianna* Antonio Virgilio Bittencourt Bastos**
}

$\mathbb{R} \mathbb{E} \cup \mathbb{M} O$

presente estudo apóia-se no referencial sócio-construtivista, especialmente em conceitos e idéias desenvolvidas por Karl Weick, para analisar uma experiência de avaliação de um programa de desenvolvimento de pessoas - "Cuidar-se para cuidar" - em uma instituição hospitalar da rede privada de Salvador. Todas as decisões do processo de concepção e desenvolvimento da avaliação do programa realizada por uma equipe de consultores externos e técnicos do Hospital foram registradas. Tais dados fornecem a base para as análises e interpretações que buscam ressaltar a natureza socialmente construída dos processos organizativos. Os resultados evidenciam, em primeiro lugar, que o contexto da organização e as suas políticas de Recursos Humanos favorecem processos de sensemaking posteriores e incremento de uma 'mente coletiva'. Em segundo lugar, são revelados, nas diferentes fases do processo de avaliação, os schemas que guiam todo o processo de construção de sentido e do seu compartilhamento na equipe. A análise dessa experiência aponta, de forma significativa, como o processo de avaliação de programas constituiu, na realidade, uma prática organizativa que dá estabilidade às experiências individuais e contribui para a construção de sentidos compartilhados entre as pessoas, articulando-os a valores e missão da organização.

$A B S T R A C \mathbb{T}$<smiles>C1CC2C(C1)C1CC21</smiles>

he present study, based on concepts from a cognitive and constructivist perspective of the organization, specially on the concepts and ideas of Karl Weick, analyzes the experience of evaluation of a program, developed in a private hospital in Salvador ("Care for yourself to care for others"). The program was evaluated by external consultants and technicians from the hospital team as well. the data collection and analysis focused on evaluating the decision-making process related to the conception and development of the program. These data, systematically recorded, were the basis for discussion and interpretations that emphasized a socially constructed nature of the processes of organizing. first of all, the results make evident that the organizational context itself, as well as the policies of Human Resources, favor sensemaking processes later and and the development of a collective mind, contributing to make the organization leaders vigilant and attentive so that the moral values and knowledge are duly contemplated. Secondly, the schemes which guide the whole process of sensemaking and how it is shared by the team are clearly shown in the different phases of the evaluation process. The analysis of this experience indicates, in a very significant way, how the evaluation process constituted, in fact, an organizative practice that provides stability to individual experiences and contributes to the sensemaking shared among people, articulating them to the organization's values and mission. 
presente trabalho toma como objeto privilegiado de análise o processo de avaliação dos resultados de um programa que se insere em um conjunto de ações que implementam a política de desenvolvimento de pessoas de uma instituição hospitalar. O foco, contudo, não é o programa em si, nem a sua avaliação, algo que já foi objeto de outra comunicação (BASTOS, FERNANDES e VIANNA, 2003). Na realidade, no presente artigo, toma-se o programa e as ações da consultoria para a sua avaliação como oportunidade para explorar, em uma perspectiva sócio-construcionista, os processos de organização (organizing), aqui entendidos como aqueles que geram sentidos compartilhados e articulam cognições e ações dos indivíduos e grupos em torno de objetivos. Trata-se, portanto, de uma análise do processo que envolveu consultores, técnicos e funcionários da organização e que permitiu, devido ao seu acompanhamento sistemático, acesso a fenômenos que, em uma perspectiva sócio- construcionista, estão na base ou na ontogênese da organização como um fenômeno coletivo.

A título de fundamentação teórica, após uma apresentação do campo de estudos organizacionais para localizar a perspectiva adotada neste trabalho, nos detemos na discussão do conceito de sensemaking, desenvolvido por Karl Weick, pela centralidade que o mesmo ocupa na análise do fenômeno estudado.

\section{Os $\mathbb{P} \mathbb{E}$ YOMIENOS ORGANIZACIONAIS E SEUS}

\section{$\mathbb{N} \mathbb{T} \mathbb{E} I S$ DE $\mathbb{A} \mathbb{N}$ AISE}

Os Estudos Organizacionais caracterizam-se pela extrema diversidade em termos de propostas de análise. Muitos são, também, os esforços de mapeamento das diversas abordagens vigentes no campo. Há um relativo consenso que o campo dos estudos organizacionais é, essencialmente, pluriparadigmático e pluralístico, o que o caracteriza por tensões internas de diversas ordens, além daquela que polariza a produção de conhecimento científico e a sua aplicação à realidade das organizações. Na realidade, uma grande clivagem no campo reporta-se às perspectivas macro e micro orientadas de apreensão dos processos organizacionais.

As abordagens macro e micro de fenômenos organizacionais se constituíram, segundo Bastos (2000), separadamente, construindo e problematizando seus objetos de investigação de formas diferentes. De modo geral, a primeira esteve preocupada com as organizações totais, suas relações com o ambiente e outras organizações; a segunda, por sua vez, voltou-se para investigação de processos nos seus ambientes internos. Um quadro de referência importante para a compreensão das tensões que marcam a construção teórica sobre organizações nos é oferecido por Pfeffer (1985). O autor define dois eixos ou dimensões distintas nas quais teorizações no campo podem ser estruturadas.

A primeira dimensão é o nível de análise que a teoria se propõe a investigar. Existem dois níveis de análise relevantes para caracterizar as várias teorias organizacionais: teorias que tratam a organização como uma coletividade diferenciada e aquelas que lidam com unidades sociais menores dentro das organizações, como indivíduos, coalizões e subunidades. Associados à definição dos níveis de análise, aparecem os clássicos dilemas entre o comportamento individual e organizacional, e a análise de processo versus estrutura. Segundo Pfeffer (1985), trabalhar nessa perspectiva forneceria uma "promessa de que um tratamento mais coerente teoricamente e mais compreensivo dos fenômenos organizacionais é possível" (p. 383).

A segunda dimensão reporta-se à perspectiva adotada, implícita ou explicitamente, por cada teoria, em relação à ação. Neste sentido, Pfeffer (1985) identifica três perspectivas: na primeira, a ação é vista como intencional, racional ou 
racional limitada, sendo prospectiva; na segunda, a ação é vista como externamente limitada ou determinada situacionalmente; finalmente, na terceira, a ação é vista como algo mais randômico e dependente de um processo contínuo e emergente, com a racionalidade sendo construída depois do fato, para dar sentido aos comportamentos que já ocorreram. Tal discussão é central no campo dos estudos sobre cognição e organização, como bem documentam Schneider e Angelmar (1993), Spender (1998), Lord e Maher (1989, 1991), Walsh (1995) e Tenbrunsel, Galvin, Neale e Bazerman (1996).

No entanto, embora a necessidade de se atentar para a importância do nível de análise e para a concepção de ação adotada seja evidente, as abordagens macro e micro, segundo Staw e Sutton (1993), têm-se restringido às divisões do campo em suas disciplinas específicas. Para os autores, essa bifurcação do campo é fonte de confusão, não ficando claro se tais vertentes se referem à unidade de análise que é efetivamente explicada ou às disciplinas que fornecem a base conceitual para tais explicações.

Caso a referência seja a unidade de análise, o significado dessa divisão é pouco claro, já que a pesquisa nos contextos organizacionais varia do estudo de membros individuais, passando por grupos, departamentos, organizações e, finalmente, populações de organizações. No entanto, para Staw e Sutton (1993), se a referência são as disciplinas, essa dimensão é constantemente utilizada de forma inapropriada. Sobre esse uso, os autores afirmam (p. 351):

A palavra micro é estreitamente interpretada para indicar que a teoria psicológica é usada para explicar o comportamento de indivíduos (ou, no máximo, díades ou grupos). A palavra macro é freqüentemente interpretada para indicar que a teoria sociológica explica o comportamento no nível organizacional ou populacional.

Uma conseqüência direta desse alinhamento entre unidades de análise e disciplinas tem sido a perda de interdisciplinaridade na pesquisa organizacional, acarretando limites na capacidade de explicar o comportamento organizacional complexo.

Staw e Sutton (1993) esboçam, então, o que seria uma racionalidade para a psicologia macro-organizacional. Em síntese, essa lógica implica admitir que variáveis tidas como micro podem gerar produtos localizados como macro, o que termina por quebrar esse alinhamento de disciplina com unidade de análise. Três explicações são propostas pelos autores.

A explicação alternativa mais radical é que as ações de uma organização podem ser, de fato, o comportamento individual, ou seja, o comportamento de um indivíduo pode responder pelo comportamento da organização. Para Staw e Sutton (1993), as ações individuais e organizacionais não são apenas paralelas nessas instâncias, elas são a mesma coisa. A segunda alternativa colocada pelos autores é que indivíduos poderosos podem conduzir organizações. Mesmo considerando a influência de fatores externos na organização do negócio, os autores consideram várias formas nas quais a organização é moldada pelas idéias daquele(s) que está(ão) no poder.

Em consonância com outros autores, Staw e Sutton (1993) observam que as idéias do fundador de uma organização, ou de outros líderes, podem modelar essa mesma organização, por exemplo: tomando decisões estratégicas; formando atributos organizacionais, como estruturas, procedimentos e tecnologias; ou, ainda, construindo percepções sobre mudanças em padrões-chave organizacionais, e, finalmente, formando indivíduos que compõem a organização.

Finalmente, a terceira explicação alternativa é a de que a organização pode ser formada pelo comportamento agregado de vários indivíduos. Staw e Sutton (1993) discutem três aspectos comportamentais que, quando agregados, podem moldar a organização. Os atributos estáveis, segundo os autores, podem garantir uma auto-sustentação para a organização. Assim, a cultura, os valores prevalecentes, a estrutura e as estratégias básicas de uma firma são todos dependentes do agregado de indivíduos que fazem a organização. 
A idéia da auto-sustentação pode ser sintetizada na tendência das organizações a se tornarem homogêneas, com um grupo de 'traços de personalidade' e 'tendências comportamentais' que prevaleçam. Essa característica emerge de vários processos. A composição demográfica de uma determinada organização tende a se tornar mais homogênea já que pessoas similares aos seus membros têm maior probabilidade de serem atraídas e de serem selecionadas por aqueles responsáveis pela contratação. Ainda neste sentido, uma vez pertencente à organização, as práticas de socialização tendem a direcionar indivíduos para as normas existentes, sendo que aqueles que apresentam comportamento inadequado têm maior probabilidade de deixar a firma (STAW e SUTTON, 1993). Por fim, as crenças individuais agregadas podem ter grande poder organizativo. Dois argumentos básicos são levantados por Staw e Sutton (1993). O primeiro é o de que a organização reflete a soma das tendências cognitivas individuais de seus membros. O segundo coloca que a ação agregada não reflete simplesmente a soma de tendências individuais, mas, sim, acentuaria essas tendências configurando um fenômeno de grupo.

A discussão das tensões e dificuldades conceituais e metodológicas associadas aos diferentes níveis de análise dos fenômenos organizacionais busca fundamentar a proposta do presente trabalho que toma a noção de sensemaking, ou construção de sentido, como estratégia que possa vir a superar essa cisão entre as vertentes macro e micro orientadas. No próximo segmento, esse conceito central do pensamento de Karl Weick é apresentado.

\section{A NOÇÃO DE SENSEMAKING: A PROPOSTA DE KARL WVEICK}

PARA ANÅLISE ORGANIZACIONAL

As organizações se caracterizam por constante pressão em direção a uma subjetividade genérica. Esse tipo de subjetividade permite a criação de estruturas de controle, implicando, por exemplo, em um tipo de socialização suave, redução de recursos dispersos, legitimidade diante de acionistas, mensuração de produtos etc. É um tipo de subjetividade que, afirma Weick (1995), faz as pessoas acreditarem que as coisas estão sob controle, desde que não olhem muito perto. Embora tal cenário seja interpretado por estudiosos por meio de conceitos tais como cultura, controle organizacional e exercício de poder, o seu cerne consiste nos processos de sensemaking.

De forma articulada, duas imagens são elucidativas da forma como K. Weick pensa e analisa o fenômeno organizacional: primeira, a organização é vista como mente coletiva; e na segunda, a organização como um sistema de sensemaking. A organização como mente coletiva pressupõe que, ao contrário da noção clássica de organização como um sistema racional e estruturado, é possível concebê-la como um sistema frouxamente unido ou, ainda, fragmentado. A idéia de mente coletiva emerge para fazer frente a essa fragmentação, sendo entendida como um processo estruturante desse mesmo sistema. Assim, a mente coletiva está localizada nos processos de inter-relação.

Tais processos se caracterizam por serem compostos de interação social com determinadas qualidades. Mente coletiva não significa algo reificado, e sim uma qualidade dos sistemas de relações (BASTOS, 2000). A mente coletiva, portanto, emerge das práticas de interação social quando estas são conduzidas cuidadosa e atenciosamente. Agir dessa forma significa agir criticamente, consistentemente ou, ainda, com propósito, atentamente, de modo estudado e vigilante.

Em resumo, é possível pensar que a presença de uma mente coletiva forte implica, também, um sistema mais fortemente estruturado. A construção dessa mente coletiva apóia-se nos processos de construção e compartilhamento de sentido, algo que embasa a imagem, desenvolvida por Weick, de organização como um sistema de sensemaking. 
Pela centralidade do conceito de sensemaking no presente estudo, torna-se importante detalhar melhor esse conceito central no pensamento de Weick.

Sensemaking é um termo criado para designar o processo de construção de sentidos no âmbito das organizações. Uma citação de Czarniwska-Joerges (apud WEICK, 1995, p. 36) ilustra bem a noção:

Uma pedra existe independentemente da nossa cognição, mas a criamos a partir de um enquadre cognitivo, concentrando nossa atenção nela. A partir dessa chamada para a vida, ou para a nossa atenção, a pedra pode ser construída socialmente com a ajuda do conceito de pedra, suas propriedades e usos.

Sensemaking designa tanto um processo que fala do organizar quanto da organização. Para Weick, o processo de sensemaking pode ser localizado tanto na atividade individual quanto na atividade social. Internamente, o produto deste processo ganha forma de um mapa com asserções do tipo "se, então", no qual determinadas ações são relacionadas a determinados resultados. Externamente, esse produto toma a forma de uma construção visível para outros que não o próprio ator.

Esta noção não se confunde com outros fenômenos como cognição, percepção e representação. Ao contrário destes, sensemaking seria um processo ativo, mas o problema é que muitas das imagens associadas a esses fenômenos são passivas e implicam em aceitar o ambiente como dado.

Sensemaking pode ser analisado em quatro níveis: o nível intrasubjetivo procura dar conta dos processos individuais; o nível intersubjetivo tem um caráter comunicativo e as mudanças são frutos de sínteses de diálogo; o nível da subjetividade genérica é o pano de fundo para construção da ação organizada - seres humanos concretos não estão mais presentes, o que existe é um self genérico, categórico e abstrato (schemas, scripts etc); por fim, o nível da extra subjetividade é identificado como a cultura de um local - um self genérico que se ocupando de regras é agora substituído por significado. Ao contrário do que se tem ressaltado na própria literatura organizacional, a noção de sensemaking coletivo significa mais do que simplesmente valores ou significados compartilhados, sendo que a experiência compartilhada seria o determinante neste processo.

Para Weick (1995), os estudos de sensemaking em organizações devem partir de algumas suposições que representem o espaço no qual esse processo ocorre. São idéias implícitas em qualquer estudo em sensemaking organizacional: a) o foco básico é no processo de organizar. Como as ações se tornam coordenadas num mundo de múltiplas realidades? b) uma resposta para essa questão está na forma social que gera entendimentos intersubjetivos únicos e vívidos que podem ser tomados e enriquecidos por pessoas que não participaram da construção inicial; c) existe sempre uma perda de entendimento quando a intersubjetividade se transforma em subjetividade genérica. A função de formas organizacionais é gerenciar essa perda mantendo-a pequena e permitindo que ela seja renegociada; d) manejar uma transição é manejar a tensão que daí resulta quando as pessoas tentam reconciliar a inovação inerente à intersubjetividade e o controle inerente à subjetividade genérica. Formas organizacionais representam operações de ligação que tentam essa reconciliação; e) a reconciliação é realizada por coisas como rotinas de intercomunicação e padrões de ação habituais; f) finalmente, as formas sociais de uma organização consistem, basicamente, de atividades padronizadas e mantidas por atividade de comunicação contínua, durante as quais os participantes desenvolvem entendimentos equivalentes sobre questões de interesse comum.

Sensemaking é noção analítica que contempla tanto os aspectos processuais quanto de conteúdo relativos à experiência. Pensar no processo é, necessariamente, pensar em situações que desencadeiam esforços de sensemaking. Vale ressaltar que a construção e organização de uma determinada realidade podem começar a partir das crenças de um indivíduo ou grupo, ou ainda, a partir da ação e posterior justificação da mesma. O Quadro 1 descreve algumas situações típicas que propiciam os processos de sensemaking. 


\section{Quadro 1 - Características de Situações Ambíguas ou em Mudança}

\section{Características}

\begin{tabular}{|c|c|}
\hline $\begin{array}{l}\text { A natureza do problema em } \\
\text { questão }\end{array}$ & $\begin{array}{l}\text { O problema não está claro. Gerentes têm apenas } \\
\text { definições vagas e concorrentes do problema. } \\
\text { Freqüentemente, o problema é atravessado por } \\
\text { outros problemas. }\end{array}$ \\
\hline $\begin{array}{l}\text { A informação (quantidade e } \\
\text { confiabilidade) é problemática }\end{array}$ & $\begin{array}{l}\text { Quando há duvidas na definição do problema, } \\
\text { colecionar e categorizar informações torna-se } \\
\text { também problemático. O fluxo de informação } \\
\text { ameaça deixá-las em excesso ou insuficientes. } \\
\text { Os dados podem estar incompletos ou dúbios. }\end{array}$ \\
\hline $\begin{array}{l}\text { Interpretações múltiplas e } \\
\text { conflitantes }\end{array}$ & $\begin{array}{l}\text { Sobre os dados existentes, os gerentes } \\
\text { desenvolvem interpretações múltiplas e } \\
\text { conflitantes. Os fatos e sua significância podem } \\
\text { ser interpretados de diferentes maneiras. }\end{array}$ \\
\hline $\begin{array}{l}\text { Orientação de valores diferentes, } \\
\text { crises políticas e emocionais }\end{array}$ & $\begin{array}{l}\text { Sem critérios objetivos, os gerentes apóiam-se } \\
\text { em valores pessoais e profissionais para dar } \\
\text { sentido à situação. O conflito entre valores } \\
\text { diferentes freqüentemente sobrecarregam } \\
\text { politicamente e emocionalmente a situação. }\end{array}$ \\
\hline $\begin{array}{l}\text { Os objetivos não estão claros ou, } \\
\text { ainda, são múltiplos e conflitantes }\end{array}$ & $\begin{array}{l}\text { Gerentes não se afinam com objetivos coerentes } \\
\text { e claramente definidos. Os objetivos podem } \\
\text { estar vagos ou estão claramente definidos mas } \\
\text { contraditórios. }\end{array}$ \\
\hline $\begin{array}{l}\text { Tempo, dinheiro ou atenção estão } \\
\text { faltando }\end{array}$ & $\begin{array}{l}\text { Uma situação difícil torna-se caótica pela } \\
\text { presença de quantidades severas de um ou mais } \\
\text { dos itens mencionados acima. }\end{array}$ \\
\hline $\begin{array}{l}\text { Contradições e paradoxos } \\
\text { aparecem }\end{array}$ & $\begin{array}{l}\text { Situações têm aparentemente detalhes, relações } \\
\text { ou demandas inconsistentes. }\end{array}$ \\
\hline $\begin{array}{l}\text { Regras são vagas, } \\
\text { responsabilidades não estão claras }\end{array}$ & $\begin{array}{l}\text { Gerentes não têm um grupo claramente definido } \\
\text { de atividades que esperam desempenhar. Em } \\
\text { questões importantes, o "locus" da tomada de } \\
\text { decisão e outras responsabilidades são vagos ou } \\
\text { disputados. }\end{array}$ \\
\hline Inexistência de medidas de sucesso & $\begin{array}{l}\text { As pessoas estão inseguras sobre o que } \\
\text { significaria o sucesso na resolução de uma } \\
\text { situação, e/ou não tem formas de acessar o } \\
\text { grau em que foram bem sucedidos. }\end{array}$ \\
\hline $\begin{array}{l}\text { Entendimento pobre de relações de } \\
\text { causa e efeito }\end{array}$ & $\begin{array}{l}\text { Gerentes não entendem o que causa o que na } \\
\text { situação. Mesmo se estão certos sobre os efeitos } \\
\text { que desejam, não estão certos como obtê-los. }\end{array}$ \\
\hline Uso de símbolos e metáforas & $\begin{array}{l}\text { Em lugar de definições precisas ou argumentos } \\
\text { lógicos gerentes usam símbolos ou metáforas } \\
\text { para expressar seus pontos de vista. }\end{array}$ \\
\hline $\begin{array}{l}\text { Participação fluida nos processos de } \\
\text { tomada de decisão }\end{array}$ & $\begin{array}{l}\text { Os tomadores de decisão e acionistas influentes } \\
\text { mudam como jogadores entrando e saindo da } \\
\text { arena de decisão. }\end{array}$ \\
\hline
\end{tabular}

Fonte: Weick (1995), a partir do trabalho de McCaskey - The executive Challange:

Managing change and ambiguity.

Segundo Weick (1995), as situações ambíguas e incertas acionam processos de sensemaking. Todas essas situações podem caracterizar uma interrupção num fluxo de eventos, fazendo com que algo estranho em forma de surpresa chame a atenção de alguém. A partir de algumas pistas do ambiente, inicia-se um processo que, para o autor, tem algumas propriedades gerais: sensemaking está relacionado a processos de identidade, tem um caráter retrospectivo e social, tem origens em ambientes sensíveis que dão origem a pistas salientes e é guiado mais por plausibilidade do que por acuracidade. 
As ações organizacionais que configuram estratégias e políticas de Recursos Humanos podem ser descritas em termos do seu caráter organizativo e a sua administração como eficaz ou não, na medida em que contribui para a produção de sentidos legitimados pelas demais instâncias da organização. Nos termos de Weick (1979), o propósito é investigar como as ações nessa área contribuem para a gramática ou código, que é o organizar. Anterior e ao longo do curso das ações, estão os processos de sensemaking.

Assim, sensemaking, ou os processos de construção de sentidos no âmbito organizacional, constitui o alvo de investigação deste trabalho. Dentro deste enfoque, a Administração de Recursos Humanos passa a ser caracterizada como parte de um sistema de produção de sentidos, processo que norteou a análise do caso. Esses sentidos, por sua vez, quando incorporados à subjetividade genérica, podem contribuir, efetivamente, para o organizar, tendo suas ações legitimadas diante de outros setores e níveis hierárquicos.

O presente estudo analisa o processo de avaliação de um programa de qualificação de empregados de um hospital particular, buscando descrevê-lo como uma instância de construção coletiva de significados, congruentes com a 'subjetividade genérica' que caracteriza o padrão cultural da instituição.

\section{(O) $\mathbb{E} S \mathbb{E} \mathbb{N}$ VIVIMIENTO DO ESTUDO:}

\section{DECISOER $\mathbb{E} \mathbb{E} \mathbb{E} T$ ODOLÓGICAS}

Este trabalho, como assinalado anteriormente, analisa a experiência de avaliação do programa implantado pelo setor de Recursos Humanos de uma Unidade Hospitalar privada, de médio porte e reconhecida como de excelência na região em que atua. Tratava-se de avaliar os impactos do programa "Cuidar-se para cuidar" sobre o seu público-alvo, fundamentalmente profissionais de saúde da organização, de modo a justificar a continuidade dos investimentos no conjunto de atividades que o programa envolvia. Em linhas gerais, o programa consistia de um conjunto de vivências e reflexões que favorecessem o auto-conhecimento e ampliassem a capacidade dos profissionais em lidar com seus limites pessoais ao interagir com as situações de trabalho geradoras de estresse, tensão e sobrecarga emocional.

O processo de avaliação do programa, em si, envolveu três fases: na primeira, foi feito um levantamento de indicadores para elaboração de uma matriz que permitisse uma caracterização inicial dos produtos e resultados previstos para o programa, em termos de competências, habilidades, atitudes e valores esperados dos seus egressos; na segunda, foram criadas rotinas de comunicação para validação da matriz, no sentido de estabelecer um consenso sobre a relevância dos indicadores; finalmente, na terceira, foi realizado o delineamento da estratégia geral de avaliação que envolveu: a) captar o nível de aprendizagem resultante do programa e o quanto tais aprendizagens estavam sendo utilizadas no cotidiano dos atores; b) confrontar auto e hetero-avaliação (como essa transferência de aprendizagens no programa para o cotidiano de trabalho era vista pelo participante e pelo gerente do setor em que atuava; e c) estimar os resultados do programa no nível organizacional, quer em termos de ganhos de produtividade, quer de realização de valores centrais da organização.

Para a condução do processo de avaliação que, pelo caráter da consultoria, buscava, adicionalmente, desenvolver tal competência na equipe de recursos humanos da Instituição, foram realizadas entrevistas individuais e coletivas, assim como a aplicação de questionários aos participantes do programa e aos gestores da organização. A definição dos passos do processo, assim como o conteúdo e estrutura dos instrumentos para coleta de dados foram definidos, sempre, em interação com o grupo de participantes da Instituição. Tais instrumentos geraram os dados sobre o impacto do programa, tanto no plano dos indivíduos quanto no plano dos processos de trabalho. Todo esse processo foi monitorado, fazendo-se registros das decisões e resultados gerados em todas as suas etapas. 
A base do presente texto consistiu, portanto, no conjunto de dados coletados ao longo do processo de avaliação aos quais se agregaram informações oriundas de uma entrevista com a gerente de recursos humanos. O trabalho aqui relatado, portanto, consiste em uma análise deste processo à luz dos conceitos desenvolvidos por Karl Weick, não sendo seu objetivo a avaliação do programa em si.

\section{RESULTADOS E DISCUSSÃO}

Congruente com o referencial teórico adotado, os resultados estão estruturados em dois grandes segmentos.

O primeiro procura descrever elementos que caracterizam a organização como uma totalidade ou, em outras palavras, o contexto amplo em que o processo objeto da análise ocorreu. Busca-se descrever a organização enquanto contexto no qual o "cuidar-se para cuidar" atua, construindo parte da ação organizada. Nesse momento, o conceito de 'mente coletiva' subsidiou todo o processo de análise.

O segundo segmento detém-se no exame do processo de avaliação do programa em si, buscando explorar elementos do processo de construção de sentido durante a avaliação do programa. Mais precisamente busca-se evidenciar como o processo de avaliação, na forma como desenvolvido pela consultoria, constituiu uma instância produtora de sentidos e, em decorrência, atuou como elementos que organizam a ação do grupo de participantes. Nesse segundo momento, o conceito de 'sensemaking' joga o papel central no processo de análise da experiência.

\section{A ORGANIZAĞ́̃ ENQUANTO CONTEXTO}

O primeiro nível de análise foi guiado fortemente pelo conceito de "mente coletiva", como desenvolvido e refinado por Roberts \& Weick (1993). Buscou-se, em informações sobre valores e práticas, identificar elementos ou atributos que configuravam, na organização, um tipo especial de inter-relação tido pelos autores como fundamental para o processo de organizar. Como dito anteriormente, esse tipo de inter-relação pode ser observado na ação caracterizada por uma disposição para agir de modo vigilante e atento. Esse padrão pode ser colocado como propiciado e mantido pelo contexto organizacional amplo.

Os elementos que definem esse contexto amplo encontram-se, como formulados pela própria organização, no Quadro 2. A partir de tais definições, foram explorados missão, valores, pilares de atuação, foco estratégico e, principalmente, o modelo de gestão de RH. Essa etapa procurou identificar o conjunto de elementos que propiciam o desenvolvimento de uma mente coletiva ou, em outras palavras, um conjunto extenso de cognições e padrões de ação que são compartilhados amplamente pelos atores organizacionais.

Quadro 2 - Contexto Amplo do Trabalho de Consultoria

\section{MISSÃO VALORES}

- $\quad$ Cuidar de vidas utilizando técnicas fundamentadas em princípios humanísticos, científicos e éticos, e apoiadas no compromisso com clientes, funcionários, ramo de negócios e comunidade em geral
- Excelência

- Integridade

- Aperfeiçoamento

\begin{tabular}{llll}
\hline & & PILARES DE ATUAÇÃO & \\
& FOCO ESTRATÉGICO & \\
\hline- & Pessoas & $\bullet$ & $\begin{array}{l}\text { Qualidade no atendimento ao } \\
\text { cliente e desenvolvimento de } \\
\text { pessoal }\end{array}$ \\
\hline & Ambiente & & Tecnologia \\
\hline
\end{tabular}


Para caracterização do contexto, o estudo, apoiou-se no modelo 'communityagency' desenvolvido por Rousseau e Arthur (1999). Esse modelo híbrido engloba duas noções que possibilitam firmas e trabalhadores responderem de forma flexível às mudanças do mercado enquanto procura estabilidade, recrutando, desenvolvendo e retendo pessoas cujos talentos são críticos para a organização. Segundo os autores, esta dupla pressão - flexibilidade estabilidade - é a essência do papel da administração de Recursos Humanos contemporânea.

De um modo geral, a idéia de agency refere-se à habilidade de atores (pessoais, grupos, firmas, acionistas) tomarem decisões e agirem de acordo com seus interesses. A figura do empreendedor autônomo é prototípica, envolvendo também noções de projeção e autonomia. Ao contrário, a idéia de community referese à participação de atores em relações de interdependência e envolve expressões como suporte mútuo, cooperação e adaptação coletiva ao ambiente, além de desenvolvimento interno e afiliação. O homem organizacional comprometido é exemplar (ROUSSEAU; ARTHUR, 1999).

No âmbito das políticas de Recursos Humanos, Rousseau e Arthur (1999) descrevem esse modelo híbrido em seis dimensões distintas: o processo de admissão de funcionários, primeira dimensão, focaliza não somente o recrutamento de indivíduos, mas também a construção de relações entre eles. O aprendizado enfatiza, além de treinamento clássico, desenvolvimento e socialização, a criação de relações dentro e fora da firma. O desempenho esperado focaliza produtos individuais, do grupo e da firma como um todo. Tratando-se de empregabilidade, a quarta dimensão estipulada pelos autores, a firma prevê mobilidade interna e externa para o funcionário. Quanto aos benefícios, há uma flexibilidade em responder às necessidades de mudanças, como escolha de parceiros profissionais, horas de trabalho etc. Por fim, no término da relação formal entre trabalhador e firma, o foco está na continuidade da parceria (ROUSSEAU e ARTHUR, 1999).

O Quadro 3 sintetiza as características identificadas na organização, tendose explorado, em conformidade com o modelo adotado, as dimensões das políticas que embasam a gestão de pessoas na organização, conforme Rousseau e Arthur (1999).

Ao se examinarem as práticas identificadas em cada uma das dimensões, é possível observar um sistema de gestão de Recursos Humanos caracterizado por um modelo híbrido que, no entanto, apresenta forte direcionamento para o pólo 'community".

Os elementos que evocam a noção de community podem ser pensados como os responsáveis pelo desenvolvimento de uma mente coletiva. Os programas de capacitação geral e as políticas de não terceirização favorecem a permanência e a afiliação do funcionário para com a organização, possibilitando a construção de relações e aprendizagem em grupo; o foco no desenvolvimento de equipes de trabalho e a autonomia gerencial, também, respondem pela criação de relações dentro da firma.

Alguns elementos da noção de agency também estão presentes no modelo de gestão. Como é possível verificar, a organização procura desenvolver e capacitar seus funcionários em várias dimensões, como ensino fundamental e desenvolvimento de habilidades técnicas. Outros aspectos dessa noção são, ainda, uma conseqüência direta da dominância da organização perante seu ambiente. Por ser um Hospital de referência, esta organização termina por preparar o funcionário para um possível desligamento no futuro, assegurando a possibilidade de mobilidade externa. 


\section{Quadro 3 - Práticas Organizacionais que Permitem Localizar a} Organização no Continuum Agency/Community

\begin{tabular}{|c|c|c|}
\hline $\begin{array}{l}\text { Dimensões do } \\
\text { modelo }\end{array}$ & PROCESSOS & $\begin{array}{c}\text { Práticas identificadas } \\
\text { na instituição }\end{array}$ \\
\hline ADMISSÃO & $\begin{array}{l}\text { - Recrutar; } \\
\text { - Construir relações. }\end{array}$ & $\begin{array}{l}\text { - } \text { Confraternizações } \\
\text { freqüentes; } \\
\text { - Programas de integração }\end{array}$ \\
\hline APRENDIZAGEM & $\begin{array}{l}\text { - Colaborar com trabalhadores no } \\
\text { percurso do próprio } \\
\text { desenvolvimento; } \\
\text { - Treinar / desenvolver; } \\
\text { - Socializar; } \\
\text { - Criar redes dentro e fora da } \\
\text { firma; } \\
\text { - Desenvolver habilidades para } \\
\text { novas oportunidades de } \\
\text { mercado. }\end{array}$ & $\begin{array}{l}\text { - Autonomia de equipes } \\
\text { para decidirem sobre o } \\
\text { próprio treinamento; } \\
\text { - Programas de } \\
\text { desenvolvimento intra e } \\
\text { inter equipes; } \\
\text { - Atividades de lazer e } \\
\text { cultura; } \\
\text { - Programas de incentivo } \\
\text { à participação em eventos } \\
\text { dentro e fora da } \\
\text { organização; } \\
\text { - Programas de qualificação } \\
\text { e reciclagem de } \\
\text { profissionais. } \\
\end{array}$ \\
\hline $\begin{array}{l}\text { AVALIAÇÃO DE } \\
\text { DESEMPENHO }\end{array}$ & $\begin{array}{l}\text { - Produtos: individual, do grupo } \\
\text { e da firma }\end{array}$ & $\begin{array}{l}\text { Formação de grupos } \\
\text { para realização de } \\
\text { tarefas; } \\
\text { - Comissões científicas } \\
\text { permanentes; } \\
\text { - Realização de simpósios } \\
\text { nas áreas de atuação do } \\
\text { Hospital. }\end{array}$ \\
\hline $\begin{array}{l}\text { EMPREGABILI- } \\
\text { DADE }\end{array}$ & $\begin{array}{l}\text { - Colaboração entre Recursos } \\
\text { Humanos e trabalhador; } \\
\text { - Mobilidade interna e externa. }\end{array}$ & $\begin{array}{l}\text { - Programa de Cargos e } \\
\text { Salários; } \\
\text { - Concurso interno para } \\
\text { ocupação de cargos; } \\
\text { - Corpo clínico aberto. } \\
\end{array}$ \\
\hline BENEFİCIOS & $\begin{array}{l}\text { Flexibilidade em responder } \\
\text { às necessidades de mudanças, } \\
\text { incluindo escolha de parceiros } \\
\text { de trabalho, horas e outros } \\
\text { benefícios. }\end{array}$ & $\begin{array}{l}\text { Equipes autônomas: } \\
\text { - Negociação de horários } \\
\text { de trabalho, licença e } \\
\text { férias; } \\
\text { - Negociação do tipo de } \\
\text { treinamento e horário } \\
\text { durante o expediente. }\end{array}$ \\
\hline RMINO & $\begin{array}{l}\text { - Foco da continuidade de } \\
\text { relações trabalhador - firma. }\end{array}$ & $\begin{array}{l}\text { - Relações com a } \\
\text { comunidade médica; } \\
\text { - Corpo clínico aberto. }\end{array}$ \\
\hline
\end{tabular}

Fonte: Adaptado de Rousseau \& Arthur (1999): The boundaryless human resource function: building agency and community in the new economic era.

\section{A CONSTRUĢÃo e COMipartilliamento de SENTidos AO LONGO DO PROCESSO DE A VALIAÇÃO DO PROGRAMA}

Caracterizado o contexto organizacional, o segundo nível da análise envolveu o processo de avaliação do programa 'Cuidar-se para cuidar'. Nessa etapa, buscou-se caracterizar as práticas implicadas e os resultados por elas gerados no processo, e analisá-las à luz da noção de sensemaking. Explorou-se, como descrito a seguir, de que maneira tais práticas foram permitindo a construção e compartilhamento de sentidos, antes não explícitos para os próprios atores envolvidos no programa. 
Verificou-se, num primeiro momento, a dificuldade dos gestores em identificarem o quê e como avaliar. Somavam-se a esta dificuldade, as pressões relatadas pela equipe de $\mathrm{RH}$ no sentido de explicitar resultados advindos do programa. Havia um programa que se desdobrava em um conjunto de atividade; inexistia, contudo, um projeto claramente delineado dos objetivos, competências e habilidades a serem atingidos; faltavam, ainda, informações confiáveis sobre se os possíveis resultados alcançados estavam sendo relevantes para o trabalho cotidiano dos seus participantes.

Nesse primeiro momento, explorou-se a multiplicidade de interpretações sobre os resultados do programa, permitindo o levantamento de indicadores a partir dos relatos dos sujeitos. Ao formularem os objetivos do programa a partir da experiência, os participantes utilizaram múltiplas pistas oriundas dessa experiência ou da situação pessoal, quer no trabalho, quer no contexto extra-trabalho.

Pistas oriundas da participação do programa orientaram os relatos como pré-requisitos para saúde e bem estar, equilíbrio mental, atividade física e bom relacionamento com colegas. Problemas pessoais, de saúde e de relacionamento no trabalho, enfrentados por alguns dos entrevistados, da mesma forma, serviram como pistas salientes para estabelecer objetivos para o programa. $O$ fato de estarem com algum tipo de dificuldade na esfera pessoal fez com que alguns dos participantes atribuíssem melhoras ou resolução de problemas dessa natureza à participação do programa.

Por fim, a atividade desempenhada pelos entrevistados e os projetos correntes relacionados, também, foram elementos importantes para a construção de objetivos para o programa.

Os dados sobre as experiências e ganhos advindos do programa caracterizam-se, claramente, como um processo intrasubjetivo de sensemaking. Ou seja, trata-se de uma construção em bases retrospectivas a partir de pistas oriundas de projetos pessoais correntes.

Uma outra característica que marca essa primeira fase da avaliação é a quase ausência de projetos organizacionais relacionados ao programa. Quando não eram citados produtos clássicos esperados por qualquer organização corporativa, os entrevistados se limitavam a selecionar produtos numa esfera micro, como integração entre funcionários e melhoria de clima organizacional. De um modo geral, houve poucos relatos que pudessem expressar envolvimentos reais e intensos com projetos organizacionais, sugerindo pouco esforço por parte da gestão de RH em estabelecer relações de causa e efeito entre o objetivo do programa e produtos organizacionais.

Num segundo momento, a análise focalizou os esforços de sensemaking relativos a cada fase do processo de avaliação. Nesse segundo momento da avaliação, caracterizado por processos de sensemaking intersubjetivos, os membros da organização validaram os objetivos construídos por outros membros (aqueles que participaram da primeira fase). Aqui, modelos individuais puderam ser expostos, compartilhados e refinados. Dessa forma, uma nova abordagem para o programa começou a surgir a partir da criação de rotinas de comunicação, possibilitando aos grupos, mediante estratégias diversas, confrontar a relevância de objetivos construídos previamente. Esse momento no processo de construção de sentido foi muito rico. Os diversos sujeitos envolvidos puderam observar o caráter múltiplo e diversificado dos significados que a experiência proporcionou construir. Os atores envolvidos puderam, assim, decidir coletivamente sobre itens que vieram a compor a matriz de avaliação final para confecção dos instrumentos de avaliação. A experiência compartilhada revelou-se fundamental para o consenso, ressaltando que a experiência e o aprendizado individual no programa continuaram sendo individuais.

No terceiro momento da avaliação, aquele em que se delineou a estratégia geral de como avaliar, os consultores funcionaram como sensemakers. À medida que passaram a definir critérios de avaliação, não só emprestaram sentidos de suas experiências profissionais, como construíram outros, uma vez que propuse- 
ram e negociaram com a equipe técnica problemas de diversas ordens. Apoiados em um modelo de avaliação dos impactos de programas de qualificação, os consultores propuseram um conjunto de diretrizes técnicas, como por exemplo: a) captar percepções sobre o que foi aprendido e o que efetivamente foi usado no cotidiano dos atores; b) a necessidade de confrontar auto e hetero-avaliação; c) considerar em que medida as novas aprendizagens concretizavam valores centrais da organização; e d) obter uma medida subjetiva do quanto as aprendizagens desenvolvidas ao longo do programa aumentavam a produtividade no trabalho. Todos estes critérios foram utilizados para confecção dos instrumentos de avaliação.

Entre vários dados obtidos com a avaliação dos participantes e dos gestores sobre o programa (FERNANDES, BASTOS, TIRONI e VIANA, 2006), a discrepância entre as avaliações do que foi aprendido no programa e o que vem sendo utilizado no trabalho mostra-se reveladora de questões ligadas à construção de sentido no grupo. Dada a multiplicidade de objetivos (competências e habilidades) que integravam a matriz inicial de avaliação, foi possível agrupá-los em dois níveis objetivos no plano pessoal e organizacional. Nos resultados da avaliação, verificou-se uma incongruência entre o aprendido e o utilizado nos planos pessoal e organizacional.

No primeiro plano (pessoal), o conteúdo aprendido foi superior ao conteúdo utilizado. Inversamente, no plano organizacional, o conteúdo aprendido foi menor que o utilizado. Isto sugere que, no plano pessoal, os indicadores selecionados para a avaliação reduzem a experiência dos atores, não contemplando a complexidade da proposta do programa. O excesso de sentido característico da primeira fase da avaliação revela-se nos limites dos instrumentos de avaliação em darem conta da totalidade da experiência.

No plano organizacional, a avaliação de que o conteúdo utilizado é maior do que o aprendido corrobora a proposição de ausência de sentido construído para o programa nesse plano. Comportamentos estavam em prática em um nível tácito, sem abstração. Ao visualizarem comportamentos e habilidades neste plano, os atores passaram a interpretar a experiência no programa, de modo a garantir uma visão de si mesmos coerente com os objetivos esperados. Desde que tais habilidades e comportamentos não estavam formalizados nos objetivos iniciais do programa, como fruto de compilação de comportamentos socialmente esperados, eles, agora, passam a ser conectados aos objetivos do programa.

Todo o processo de avaliação, na realidade, foi guiado por schemas interpretativos. Como afirma Harris (1996), schemas se referem às estruturas dinâmicas de conhecimento, incluindo conceitos específicos, entidades e eventos usados por indivíduos para codificar e representar informações. Eles funcionam, portanto, como teorias subjetivas derivadas da experiência de alguém sobre como o mundo opera, e que guiam a percepção, memória e inferência.

A análise das entrevistas e os conteúdos verbais registrados ao longo de todo o processo permitiram a identificação de três importantes schemas que estão descritos no Quadro 4. Tais schemas que guiaram o processo de formulação de objetivos para o programa, estão diretamente relacionados com a missão organizacional de prestar serviços de saúde de qualidade e estão na base das contribuições individuais. São esses schemas compartilhados que imprimem um caráter organizado às ações do grupo, favorecendo a intercambialidade e a comunicação entre indivíduos. Se, por um lado, foi preciso atrelar o programa a projetos organizacionais, e revesti-lo de outros sentidos para estabilizar o fluxo da experiência e legitimar ações ante outras instâncias da organização, por outro, foi possível encontrar alguns schemas com grande função organizativa.

Os dados sugerem um schema do profissional de saúde fortemente estruturado e compartilhado pelo grupo. Para os atores, o fato de lidarem com questões delicadas socialmente, como vida e morte, saúde e doença, os faz procurar competências para além do saber técnico, no intuito de tornarem-se profissionais mais humanos e capacitados a lidar com estas questões. Um profissional 
que lida com clientes que se encontram numa condição fragilizada, segundo os relatos, deve estar preparado para isso. Este é um tipo de lógica que vai de encontro à imagem do profissional típico da área de saúde, visto como frio e desumano, realizando um trabalho mecanicamente.

\section{Quadro 4 - Schemas e a Construção de Objetivos para o 'Cuidar-se para Cuidar'}

\begin{tabular}{|c|c|}
\hline SCHEMAS & OBJETIVOS \\
\hline $\begin{array}{l}\text { Schema de profissional de saúde: o } \\
\text { profissional de saúde é visto como tendo } \\
\text { uma atividade que exige outras } \\
\text { competências além da técnica, pois vive } \\
\text { em situações limites que envolvem vida e } \\
\text { morte, saúde e doença. } \\
\text { Schema da situação de trabalho: a } \\
\text { situação de trabalho é também vista como } \\
\text { um fator de desgaste emocional. }\end{array}$ & $\begin{array}{l}\text { - melhor preparo para falar de assuntos } \\
\text { difíceis que envolvam paciente e } \\
\text { família; } \\
\text { - mais habilidade nas relações } \\
\text { interpessoais; } \\
\text { - aceitar e conviver melhor com as } \\
\text { diferenças das pessoas; } \\
\text { - minimizar o estresse provocado por } \\
\text { situações de trabalho; } \\
\text { - lidar com situação de conflito com } \\
\text { menos desgaste. }\end{array}$ \\
\hline $\begin{array}{l}\text { Schema do cliente: o cliente } \\
\text { (paciente e familiares) é alguém que } \\
\text { pode retirar ou sugar energia. }\end{array}$ & $\begin{array}{l}\text { - lidar com sofrimento do outro, } \\
\text { minimizando desgaste emocional; } \\
\text { - melhorar a saúde emocional; } \\
\text { - respeitar meus limites. }\end{array}$ \\
\hline
\end{tabular}

Os dados indicam que as situações de trabalho são percebidas como muito estressantes para os indivíduos. Cuidar de vidas é socialmente reconhecido como uma tarefa de alta responsabilidade e risco. Até mesmo os entrevistados que exercem atividades administrativas e de apoio colocam o cuidado com a vida e o lidar com a morte, ou a possibilidade desta, como um fator que justifica a existência de um programa desse tipo em organizações desta natureza.

Por fim, as entrevistas sugerem que schemas de paciente são, também, determinantes no processo de construção de objetivos para o programa. Os pacientes mais difíceis são percebidos como alguém capaz de retirar energia dos profissionais, assim como suas famílias, que podem desestabilizar o profissional e a equipe de trabalho por estarem na situação em que se encontram. Esse schema é bastante saliente na construção de objetivos para o programa.

Em um olhar retrospectivo sobre todo o processo de avaliação, é possível encontrar outros elementos e momentos definidores do curso da ação e, conseqüentemente, dos sentidos construídos ao longo da experiência. Um ponto a ser destacado é o primeiro olhar por parte dos consultores sobre o programa escolhido pela equipe de Recursos Humanos para ser avaliado. Os consultores chegaram à organização pelas mãos desta equipe, e não por outra. Neste sentido, foram prestar serviço a um grupo favorável à manutenção do programa na organização. Ao tentar avaliar e ensinar como avaliar um programa que pretendia instalar habilidades pouco tangíveis, a máxima "é possível avaliar" guiou o processo, ao passo que a mensuração de resultados ficou subsumida.

A decisão pela metodologia de avaliação e o processo de construção do instrumento para tal fim, podem, também, revelar aspectos relevantes de sensemaking. Ao optar por fazer um levantamento de indicadores a partir de amostra de profissionais que participaram do programa, não se contemplaram profissionais que, por algum motivo, não quiseram ou não puderam se engajar no mesmo programa. Tem-se, então, um viés na amostra produzido "quase" que intencionalmente. Da mesma forma, o processo de levantamento de indicadores priorizando a verbalização sobre resultados alcançados impediu maior acurácia. Por outro lado, ao tentar fazer ligações entre produtos do programa e um projeto organizacional, os consultores tiveram um papel diretivo.

Foi possível observar que o processo de avaliação caracterizou-se muito mais por um esforço de justificação do que de mensuração. O instrumento 
de avaliação que fará o enquadre da experiência para os próximos egressos é produto do esforço de legitimação do programa. Entretanto, do outro lado, está a crença no potencial organizativo da experiência por parte da equipe de Recursos Humanos. Ao fortalecer e difundir esquemas presentes na organização, o processo de avaliação cumpre, possivelmente, um papel não previsto. Avaliar é organizar, não muito pelo que possa eventualmente medir, mas principalmente, construir.

\section{$\mathbb{R} \mathbb{E} \mathbb{F} \mathbb{E X O} \mathbb{E S}$ FINAIS}

No estudo, a avaliação foi entendida como um processo diretor e contínuo que teve como função fornecer e gerenciar pistas para interpretação da experiência. O processo de avaliação do "Cuidar-se" pode ser visto como um mecanismo gerencial de construção de sentido que redimensiona o programa, conferindo legitimidade às suas propostas. Por outro lado, o processo de avaliação confirma, retroalimenta e fortalece um sistema interpretativo que tem se mostrado de grande importância para a organização e sua missão de prestar serviços de saúde com padrão de excelência.

Nesta perspectiva, a avaliação contemplou, além do processo e do produto - aspectos que caracterizam os clássicos processos de avaliação - processos de construção de sentido, caracterizando-a como uma instância e ocasião para sensemaking. A partir dos dados coletados, infere-se que a avaliação constituiuse num elemento organizativo. Enquanto contribuição para mente coletiva (mecanismo estruturante da vida organizada), a avaliação ressaltou pedaços da experiência antes ignorados. Enquanto contribuição para o sistema de sensemaking, a avaliação é entendida como parte deste sistema, na medida em que se constitui em mais um mecanismo de produção de sentidos.

Ressalta-se, neste momento, que a avaliação, entendida como um processo organizativo, contribui para a ação organizada de uma maneira diferenciada. Desse modo, o estudo aproximou-se de elementos importantes dessa ação e ressaltou tanto os seus determinantes, quanto processos e produtos determinados por eles. A investigação de tais elementos, assim como os processos relacionados permitem uma abordagem processual de organização, ao revelar mecanismos pelos quais indivíduos e grupos constróem sentido para suas ações.

A título de considerações finais, é possível afirmar-se que o conjunto de questionários utilizados para a avaliação deve ser visto como um mapa que forneceu pistas salientes para construção de sentidos comuns ligadas à experiência e ao território mapeado. Relações do tipo "se, então" passam a estruturar ou a formatar o processo de sensemaking, além de permitir a outros egressos do programa o acesso a códigos e linguagens específicos, dando um caráter coletivo e compartilhado aos significados. Ao fornecer essa estrutura, o questionário enseja uma leitura mais direcionada e relevante para o objeto da avaliação, permitindo aos atores um olhar para os aspectos organizacionais construídos para o programa 'Cuidar-se'.

Examinando-se o processo de avaliação, em si, é possível concluir que, na sua essência, ele funcionou no presente caso como um processo organizativo, o que não significa necessariamente um aumento de acurácia. Percebe-se uma face de arbitrariedade na seleção e escolha de problemas a serem pontuados e avaliados. Nesse sentido, a avaliação e seus produtos constituem-se num filtro por meio do qual o ambiente social é construído e interpretado. No fluxo de negociação entre consultores e equipe técnica, os sentidos negociados podem ganhar em legitimidade e possibilidade de influência. O consultor que detém conhecimento sobre um tópico tem mais condições de barganhar sentidos, incorporando aspectos de avaliação que julga mais relevantes. Entendendo sensemaking e organização como cortes do mesmo tecido, avaliar constitui-se, portanto, numa interrupção da corrente de experiência com fins de estabilizar o ambiente social. 
Finalmente, é interessante destacar o caráter heurístico da noção de sensemaking cunhada por Karl Weick. Ela permite uma perspectiva inovadora de análise de fenômenos organizacionais. Nesse sentido, uma agenda que contemple os vários aspectos da noção permitiria um fôlego maior para aqueles que estudam organização, tentando ultrapassar as barreiras disciplinares e as clássicas divisões no campo. No entanto, sensemaking, como colocado por Weick (1995), é um fenômeno da vida organizada. Como tal, está em toda parte. O formato do estudo de caso, como o que aqui foi relatado, apresenta, como limite, o seu caráter demonstrativo, revelando que o processo existe e descrevendo as características com que acontece. Novos trabalhos no campo de sensemaking e avaliação podem avançar na direção de 'desnaturalizar' elementos e schemas construídos pelos sujeitos, acentuando a possibilidade de se vir a compreender como se dá a microgênese das mudanças nos processos organizativos.

$\mathbb{R} \mathbb{E} \mathbb{E} \mathbb{R} \hat{\mathbb{E} N C I A S}$

BASTOS, A.V.B. Organização e cognição: o que emerge desta interface? In: PINA, Miguel; RODRIGUES, Suzana Braga. (Org.). Estudos Organizacionais: novas perspectivas na administração de empresas - Uma coletânea luso-brasileira. 1a. ed. São Paulo, 2000, p. 173-212.

BASTOS, A. V. B.; FERNANDES, S. R. P.; VIANA, A. V. Avaliação de programas de T\&D como contexto para aquisição de competências e aprendizagem organizacional: o caso do programa 'Cuidar-se para cuidar'. Revista Gestão e Tecnologia, Belo Horizonte, v. 1, n. 2, p. 19-41, 2003.

BURRELL, G. Ciência normal, paradigmas, metáforas discursos e genealogia da análise. Tradução de Mário Couto Soares Pinto. In: CLEGG, S. R.; HARDY, C.; NORD, R. W. (Org.) Handbook de estudos organizacionais: modelos de análise e novas questões em estudos organizacionais. São Paulo: Atlas, 1999. v. 1. 465 p.

CLEGG, S.; HARDY, C. Organização e estudos organizacionais. Tradução de Ailton Bomfim Brandão. In: CLEGG, S. R.; HARDY, C.; NORD, R. W. (Org.) Handbook de estudos organizacionais: modelos de análise e novas questões em estudos organizacionais. São Paulo: Atlas, 1999. v. 1. 465 p.

ECCLES, R.; NOHRIA, N. Retórica: o trabalho com as palavras, assumindo a responsabilidade, redescobrindo a essência da administração. Rio de Janeiro: Campus, 1994.

FERNANDES, S. R. P. ; BASTOS, A. V. B.; TIRONI, M. S. e VIANA, A.C.V. "Cuidar-se para cuidar": avaliação de um programa de desenvolvimento de pessoas de um hospital. In: BORGES-ANDRADE, J. E.; ABBAD, G.S. e MOURÃO, L. (Orgs.). Treinamento, desenvolvimento e educação em organizações e trabalho - fundamentos para a gestão de pessoas. Porto Alegre: Artmed, 2006. Cp. 29, p.558-570.

HARRIS, S. G. Organizational culture and individual sensemaking: a schemabased perspective. Organization Science, 5 (3):309-321, 1996.

LORD, R.G. e MAHER, K. J. Cognitive theory in industrial and organizational psychology. In: M.D. Dunnette e L.M. Hough. Handbook of industrial and organizational psychology, 2a. ed., vol 2, capítulo 1, p. 1-47. Palo Alto, CA: Consulting Psychologists Press, Inc., 1991.

MORGAN, G. Imagens da organização. São Paulo: Atlas, 1996.

NICOLINI et al. The social construction of organizational learning: conceptual and pratical issues in the field. Human Relations, v. 48, n. 7, p. 727-747,1995. 
PFEFFER, J. H. Organizations \& organization theory. In: LINDZEY, G.; ARONSON, E. (Orgs.). The handbook of social psychology. 3. ed., v. 1, p. 379-439. New York: Random House, 1985.

REED, M. Teorização organizacional: um campo historicamente contestado. Tradução de Jader C. de S. Silva e Marcos C. Lima. In: CLEGG, S. R.; HARDY, C.; NORD, R. W. (Org.) Handbook de estudos organizacionais: modelos de análise e novas questões em estudos organizacionais. São Paulo: Atlas, 1999, v. 1, p.61-98.

ROUSSEAU, M. D.; ARTHUR, M.B. The boundaryless human resource function: building agency and community in the new economic era. Organizational Dynamics, v. 27, n.4, p. 7-18,1999.

SCHNEIDER S.; ANGELMAR, R. Cognition in organizational analysis: who's minding the store? Organization Studies, 14(3):347-374, 1993.

SCHULTZ , A. Fenomenologia e relações sociais. Tradução de Angela Melin. Rio de Janeiro: Zahar, 1979.

SPENDER, J-C. The dynamics of individual and organizational knowledge. In: C. Eden e J-C Spender, Managerial and organizational cognition: theory, methods and research. London: SAGE, 1998, p. 13-39.

SPINK, P.K. Organização como fenômeno psicossocial: notas para uma redefinição da psicologia do trabalho. Psicologia \& Sociedade, v. 8, n.1, p. 174192, 1996.

STAW, B. M.; SUTTON, R. I. (1993). Macro organizational psychology. In: J. Keith Murninghan (Ed.). Social Psychology in Organizations - Advances in theory and research. Englewood Cliffs, NJ: Prentice-Hall, Inc. Cap 16, p. 350-384.

TENBRUNSEL, A.E.; GALVIN, T. L.; NEALE, M.A. e BAZERMAN, M.H. (1996). Cognitions in organizations. In: S. Clegg, C. Hardy e W. Nord, Handbook of Organization Studies. London: SAGE, p.148-174.

WALSH, J. P. Managerial and organizational cognition: notes from a trip down memory lane. Organization Science, 6(3):280-321, 1995.

WEICK, K. E. Cognitive processes in organizations. Research in Organizational Behavior, v. 1, p.41-74, 1979.

WEICK, K. E. Sensemaking in organizations. Thousand Oaks: Sage, 1995.

WEICK, K. E. Social psychology of organization. São Paulo: Edgard Blücher, EDUSP, 1979.

WEICK, K. E.; ROBERTS, K. H. Collective mind in organizations: heedful interrelating on flight decks. Administrative Science Quarterly, v. 38, p. 357$381,1993$.

WEICK, K. E.; WESTLEY, F. Organizational learning: affirming an oxymoron. In: CLEGG, S.; HARDY, C.; NORD, W. (Org.) Handbook of organization studies. London: Sage, 1996 . p.440-457. 